\title{
Correspondence
}

\section{Copper deficiency and non-accidental injury}

Sir,

We write to congratulate Dr Jonathon Shaw on his comprehensive and balanced review of copper deficiency in infancy and its relation to fractures diagnosed as nonaccidental injury. ${ }^{1}$ We trust that it will put an end to poorly supported attempts on the part of some expert witnesses to ascribe fractures to copper deficiency in circumstances when it is manifestly not present. These attempts have been the subject of adverse comment in the Appeal Court ${ }^{2}$ and Family Division of the High Court ${ }^{3}$ in both criminal and wardship proceedings. The waste of time, money, and emotional damage which results from the protracted and complicated legal proceedings is incalculable.

Dr Shaw together with Dr Carty, ${ }^{4}$ in the same issue of your journal have established clearly the criteria which should apply before the diagnosis of copper deficiency is considered possible and have shown that proper analysis of clinical, radiological, and laboratory criteria even in the absence of serum copper concentrations are quite adequate in most cases. It is our view, borne out by the data and arguments presented by Drs Shaw and Carty, that infants who sustain fractures but do not have recognised risk factors for copper deficiency, have normal bone structure, and no haematological abnormalities do not need to have copper and caeruloplasmin concentrations measured on clinical grounds. It is questionable whether it would be ethical to do them for purely forensic reasons in the absence of reasonable evidence suggesting that they might be abnormal. We are concerned at the prospect of multiple requests for serum copper determination. It would be unfair both to the infants and the laboratories.

While we accept that premature infants may represent a special risk group because of diminished hepatic copper reserves, many of the references cited by Shaw involve infants given outmoded parenteral feeding formulae or receiving partial enteral feeds. With the use of modern crystalline amino acid parenteral feeding solutions together with a trace element solution (supplying $0.3 \mu \mathrm{mol} / \mathrm{kg} /$ day of copper) we have found copper deficiency rare.

\section{References}

${ }^{1}$ Shaw JCL. Copper deficiency and non-accidental injury. Arch Dis Child 1988;63:448-55.

2 Regina versus Lees and Lees, Lord Justice Lane 1987.

3 Judgement of the Honorable Mr Justice Hollis in Wardship Proceedings, Middlesbrough 1987.

${ }^{4}$ Carty H. Brittle or battered. Arch Dis Child 1988;63:350-2.

L S TAITZ and C J TAYLOR Department of Paediatrics, University of Sheffield and Sheffield Children's Hospital, Sheffield S10 $2 T H$

\section{Urinary creatinine excretion in the newborn}

Sir,

Al-Dahhan et al claim that their data are only the second to report the urinary excretion rate of creatinine in preterm infants, ${ }^{\prime}$ and are apparently unaware of our 1985 paper which theirs closely mimics. ${ }^{2}$

We measured the urinary excretion rate of creatinine in babies of similar gestational ages ( 26 to 40 weeks), weights $(640$ to $3710 \mathrm{~g})$, and postnatal ages to Al-Dahhan et al, and produced almost identical results and conclusions. We found that the rate varied with weight, surface area, length, gestational age, and postnatal age, but that the relation with body weight was the most powerful, so that there was no correlation between urinary excretion rate of creatinine/ $\mathrm{kg}$ and most of the other parameters. The only difference between our findings is that we found the urinary excretion rate of creatinine $/ \mathrm{kg}$ to be slightly higher in the first week of life than subsequently. We presented these results as arithmetic means (SD) in $\mathrm{nmol} / \mathrm{kg}$ per minute. Converting to $\mu \mathrm{mol} / \mathrm{kg}$ daily our values of 104 (24) in the first week of life and 95 (19) subsequently were almost identical to the overall figure of 95.7 (33.3) reported by Al-Dahhan et al.

Al-Dahhan et al argue that a knowledge of the urinary excretion rate of creatinine should allow the urinary excretion rates of other substances to be estimated without the need for timed urine collections; in our paper we showed this to be the case for sodium and potassium. Although the $95 \%$ confidence intervals for these estimations are wide at 62 to $161 \%$, we have found them to be narrow enough to provide useful clinical information. Using our data, the daily excretion rate of a substance, $x$, per $\mathrm{kg}$ is $104 \mathrm{Ux} / \mathrm{Uc}$ for infants in the first week of life and $95 \mathrm{Ux} / \mathrm{Uc}$ for older neonates, where $U x$ is the urine concentration of the substance in units/l and Uc is the urine creatinine concentration in $\mu \mathrm{mol} / \mathrm{l}$. We proposed that for clinical usage the formula $100 \mathrm{Ux} / \mathrm{Uc}$ would be more easily memorable with little loss of accuracy. We feel that the data of Al-Dahhan et al further strengthen our conclusion.

Using the same principle, we also showed that the urine flow rate per $\mathrm{kg}$ can be estimated with a similar degree of accuracy from a knowledge of the urinary excretion rate of creatinine $/ \mathrm{kg}$ and the creatinine concentration of an untimed ('spot') urine sample. The daily urine excretion $(\mathrm{ml} / \mathrm{kg})$ is thus $104 / \mathrm{Uc}$ in the first week of life or $95 / \mathrm{Uc}$ thereafter, or can be approximated to $100 / \mathrm{Uc}$ for convenience, but it must be noted that in this case Uc is the urinary creatinine concentration in $\mathrm{mmol} / \mathrm{l}$.

\footnotetext{
References

1 Al-Dahhan J, Stimmler L, Chantler C, Haycock GB. Urinary creatinine excretion in the newborn. Arch Dis Child 1988;63:398-402.
} 